\title{
The Untenability of Atomistic Theory of Meaning
}

Satya Sundar Sethy

\begin{abstract}
Atomistic theory of meaning or 'meaning atomism' expresses that each representation either in a linguistic or mental system is completely definable by itself. It explains that meaning of a sentence is determined independently of other sentences, which implies understanding a sentence does not require any further sentences for its support because, each sentence conveys a specific sense, and it is about the state of affairs of the world. Thus, 'sense' assists to identify the referent of a sentence. A sentence is meaningful if the state of affairs is found in the phenomenal world, and if it does not find in the phenomenal world, then it is judged as meaningless sentence. Meaning of a sentence is thus determined by its truth-value that stands as referent of the sentence. In this context, the paper argues how meaning atomism is inadequate to capture the whole complexity of meaning in the language system. Further, it highlights the logical problems in atomistic theory of meaning for not being qualified as a comprehensive theory of meaning. In this regard, we have considered some of the well-known traditional theories of meaning, such as; picture theory of meaning, verifiability theory of meaning, Tarski's T-Schema, Frege's notion of sense determination of propositions among others, and offer a few crucial arguments on the failure of atomistic theory of meaning in a language system.
\end{abstract}

Keywords: Meaning, reference, picture theory of meaning, t-schema

$\mathrm{T}$ he atomistic theory of meaning or 'meaning atomism' expresses that a representation either in linguistic or mental system is completely definable by itself. It explains, meaning of a sentence is determined in isolation from other sentences of a language, which implies understanding a proposition does not require any support from other propositions of that language, and this theory is endorsed by Frege, Early Wittgenstein, Schlick, Ayer, Waismann, Alfred Tarski, and a few. For them, each sentence conveys a specific sense and it is about the state of affairs of the world. The sentence will be meaningful if the state of affairs is found in the phenomenal world, and thereby,

(c) 2013 Satya Sundar Sethy

http://www.kritike.org/journal/issue 12/sethy june2013.pdf

ISSN 1908-7330

(cc) BY-NC 
the sentence is judged as true. So there is a tight-knit association found between meaning of a proposition and its referred state of affairs. Thus, a proposition is judged as true or false is based on its referred state of affairs. If the state of affairs which conveyed by the sentence maps with the empirical world then the sentence will be judged as true, and it will be judged as false if the state of affairs does not map with the empirical world. The important idea derived from this conception of meaning is that the truth-value of a proposition determines the meaning of a proposition. Logically speaking, if a proposition does not have truth-value, it will be regarded as meaningless proposition.

A series of question arise from the above discussions, such as; Can meaning of an individual sentence be understood without relating to other sentences?; How the meaning of an individual sentence will be understood independently from other sentences?; How does a sentence convey a particular sense, and again, eternally that must about the state of affairs of the world?; How does sense assist to get the referent of it? All these questions together constitute a broad query of our discussion in this paper, i.e. what are the problems found in atomistic theory of meaning to claim its inadequacies to capture the whole complexity of meaning? Let us discuss the logical grounds on the failure of atomistic theory of meaning in any language system.

Logical positivists, such as; Ayer, Schlick, \& Waismann in confirmation to the theory 'meaning atomism' state that meaning of a proposition is the method of its verification. From this, it follows that a sentence is verifiable implies it possess certain meaning, and the 'meaning' is derived from the observational sense-data ${ }^{1}$ or the sense experiences. In this regard, Carl Hempel (1935) states that 'verifiability criterion' cannot be considered as a sole criterion to understand the meaning of a proposition. The reasons he has mentioned that there are cases where propositions are in universal form or in the form of scientific laws. These propositions are neither verified conclusively nor able to provide the complete observational sense data to establish their truth-values, but they possess meaning. So, in this case, how could we claim that these propositions are meaningless? Continuing further he enunciates that there are statements which are emotive in form or expressing moral aspirations of individuals whose cognitive value cannot be determined by verifiability method. Then, could we regard these as 'pseudohypothesis'? How should we consider them (these statements)? Can we claim that they are necessarily meaningless propositions? Thus, the verifiability criterion for determining the meaning of a proposition is enunciated with some serious lacunas. It is so because it fails to explain a proper account of meaning determination of a proposition, particularly, the complexities associated with it.

\footnotetext{
${ }^{1}$ The phrase 'observational sense-data' has introduced by Bertrand Russell on his paper "Description." See R. Ammermann ed., Classics of Analytic Philosophy (New Delhi: Tata McGraw-Hill Publishing Company Ltd., 1965).
} 
A question arises, whether the verifiability criterion for determining the meaning of a proposition is a private one or of a public sort? This question has utmost significance in this situation because in order to verify a proposition there are varieties of method available to us. In other words, there is no single method that has been prescribed to do so. We verify a proposition by the help of our sense experiences and the evidences that are accessible to us. Thus, it is claimed that the method of verifying a proposition may differ from person to person and from place to place. If it is so then how could we determine the meaning a proposition with certainty?

In view of the Logical Positivists' rigid distinctions between the analytic and synthetic propositions, it is necessary to consider the case like, where the proposition is neither analytic nor synthetic but possesses meaning, e.g. "I request him to open the door." This sentence is neither analytic, that is, true by definition, nor it is synthetic because it does not state any facts of the world. Nonetheless, it possesses meaning. So a question arises, where do we place this sentence and how to determine the logical status of it? Hence, the principle of verification cannot be applied for the determination of the meanings of such sentences.

The verifiability criterion cannot even apply to those statements which are consisting of both universal and existential quantifiers in order to acquire their meaning. For example; "For any substance there exists some solvent." This sentence consists of both universal and particular quantifiers. ${ }^{3}$ The question arises that what sort of observations lead to verify the facts stand by these propositions? It is noticed that no sentences of this kind can be logically deduced from any finite set of observation sentences. Hence, it is unverifiable and thus the sentence is not meaningful. But in reality, we understand the proposition and we also know what it expresses by virtue of its meaning. In this respect, the criterion of verifiability is found to be too defective.

Logically speaking, if there are two sentences, "The table is brown - T" and "The absolute is perfect - N" and they are conjoined with disjunctive operators where, if one is verifiable the whole sentence will be also verifiable. Symbolically speaking, if $\mathrm{T}$ and $\mathrm{N}$ are two different sentences where both are conjoined in terms of disjunctive operator $\left(\mathrm{T}_{\mathrm{V}} \mathrm{N}\right)$ where if one, such as ' $\mathrm{T}$ ' is verifiable the entire sentence ' $\mathrm{T} v \mathrm{~N}$ ' is verifiable. The reason is, if $\mathrm{T}$ is a consequence of some finite class of observation sentences, then trivially $(\mathrm{T} v \mathrm{~N})$ is a consequence of the same class. This sort of case logical positivists has not taken into their account for establishing the verifiability theory of meaning. Verifiability

2 This example has taken from C. Hempel, "Problems and Changes in the Empiricist Criterion of Meaning," in R. Ammerman, ed., Classics of Analytic Philosophy (New Delhi: Mc GrawHill Publishing Company Ltd., 1965), 218.

${ }^{3}$ Here 'particular quantifier' is to be understood same as 'existential quantifier.' The symbol for existential quantifier is ' $\square$ x.'

(C) 2013 Satya Sundar Sethy

http://www.kritike.org/journal/issue 12/sethy june2013.pdf

ISSN 1908-7330 
theory claims a sentence $\mathrm{P}$ is verifiable, and hence it has meaning, and the meaning of the sentence is derived from observational sense-data ${ }^{4}$. Considering this phenomenon, it follows that $\neg \mathrm{P}$ (negation of $\mathrm{P}$ ) cannot be verified because it is logically deduced from the rule that if $P$ is true then $\neg P$ must be false, and if $\neg P$ is true then $\mathrm{P}$ is false. If we add the quantifiers with the proposition ' $\mathrm{P}$ ' we find that 'if ' $\exists \mathrm{x}(\mathrm{Px})$ ' is true then it's negation ' $\forall \mathrm{x}(\neg \mathrm{Px})$ ' is false and vice versa. This is so because the existential quantifier says that there exists at least one thing that has the property $\mathrm{P}$ whereas, the second one or the universal quantifier says, nothing has the property $\mathrm{P}$. A question arises, if we verify the proposition $\exists \mathrm{x}(\mathrm{Px})$ and get its meaning, we can claim that $\exists \mathrm{x}(\mathrm{Px})$ is true but why can't we claim that $\forall \mathrm{x}$ $(\neg \mathrm{Px})$ is also true. Why can't we say that $\forall \mathrm{x}(\neg \mathrm{Px})$ has also meaning therefore, it must be true? If we say so, then it will be a logical error to claim that both $P$ and it's negation $\neg \mathrm{P}$ are true. In this respect the atomistic theory of meaning is too inclusive.

Further, in case of atomistic theory of meaning we don't get the meanings of the sentences which are expressed in the forms of existential hypothesis. For example, "There exists at least one dragon." It is a proposition where we are unable to explain the meaning independently from other propositions because, in order to know the meaning of this sentence, we must know what the dragon is about. It is through this process that we will know the meaning of the given proposition. Thus, the meaning of a proposition can be attained only when we know in which context it is used and what it states about. Suppose the sentence P says "All crows are black" and $\mathrm{Q}$ says "The absolute is perfect." $\mathrm{P}$ is verifiable as an atomic sentence. We get its meaning by the help of the criterion of verifiability theory because it states about the facts of the world. On the other hand, $Q$ does not state anything about the facts of the world. Hence, it is unverifiable, but we get its meaning by the help of its constituent words and by using the grammatical rules on it. Thus, it is asserted that $\mathrm{P}$ is true and $\mathrm{Q}$ is false on the account of the verifiability theory of meaning. Logically speaking, if $\mathrm{Q}$ is false then $\mathrm{Q}^{\wedge} \mathrm{P}$ (two sentences are conjoined with the logical connectives, symbolized as 'and') must be false. This is so because in case of disjunction out of two premises if one is false the conclusion will be also false, i.e. 'All crows are black and the absolute is perfect' is false. But this is wrong to say that 'All crows are black and the absolute is perfect' is a false sentence. Here, atomistic theory fails to determine the meaning of a proposition.

Let us consider another case where $\mathrm{T}$ is a sentence and it is empirically significant for satisfying the verifiability criterion of meaning. The question arises; if $T$ is a significant observable sentence then $\neg T$ is not an observable significant sentence. So $\neg \mathrm{T}$ does not have the cognitive meaning as oppose to $\mathrm{T}$. But it is

\footnotetext{
${ }^{4}$ The phrase 'observational sense-data' has introduced by Bertrand Russell on his paper "Description." See Ammermann, Classics of Analytic Philosophy.
} 
logically wrong to say so. Here, atomistic theory fails to establish the meaning of a proposition on the ground of verifiability criterion of meaning.

Carnap's expresses his views on 'meaning atomism' in his work on "The Logical Syntax of Language" (1937) and that is purely based on the mathematical logic and empirical sciences. According to him,

the matter of 'verification' is still to be approached in a syntactical way; that is, as a matter of the formal, syntactical coherence or consistency within the language of an empirical discipline, among the various propositions that compose it. So, any empirical science will need to include in its language the protocol sentences that report the findings of empirical observations. ${ }^{5}$

This view can be questioned on the ground that we cannot claim that the formal or syntactical rules are essential for doing the logical analysis of the language of science. If we do so, then it ignores the crucial semantic part of the empirical reference and it leads to the determination of the truth-value of a proposition.

It is useful to say, the meaning of a statement is the method of its verification. But to say this is not to make a claim that we can determine the meaning of a proposition once for all. This is so because in our day-to-day life, we don't think of verification when we understand the meaning of the propositions uttered by the speakers. We suggest a method of verification only after we understand the meaning of a proposition. This may be argued in the following way. If a person knows what it means that 'it is now raining' and also knows the word 'yesterday' means, then he understands the sentence "it rained yesterday." It is so because he understands the constituent words of the sentence and knows the usage of English syntax. This, however, does not mean that I know how the proposition is to be verified. Then, what is it that leads me to suggest a particular method of verification? I have learned from experience that rain leaves traces of moisture on the earth. I remember such experiences and say that on the basis of this evidence it can be determined whether it has been rained yesterday or not. ${ }^{6}$ This case clearly shows that to explain the method of verification is not to explain the meaning.

${ }^{5}$ C. Munitz, Contemporary Analytic Philosophy (New York: Macmillan Publishing Co., INC, 1981), 266.

${ }^{6}$ This example and its analysis has taken from Waismann, F. ed., "Meaning and Verification," in Essential Readings in Logical Positivism (Oxford: Basil Blackwell Publication, 1981), 52. 
Another example, "This man died five hours ago."7 This sentence has meaning and we understand it without verifying the proposition. The explanation is as follows; if I am asked whether I have understood this sentence, I would say that I do; otherwise I cannot claim that I know English. But if I am asked how do I verify the sentence, I may not be in a position what to say. Suppose it is discovered the exact time of the person by conducting certain medical tests. Still I would not say 'Ah!, now at last I understand what the sentence means.' The reason is, the meaning of the sentence had already been established before that discovery.

Wittgenstein while speaking about verification principle says that it is 'a mere of rule of thumb,' because 'verification' may not imply expressing meaning. As he argues, statements in the newspaper can verify the proposition that Cambridge had won the boat race, and that yet these statements 'only go a very little way towards explaining the meaning of 'boat-race." ${ }^{\text {' }}$ Thus, verifiability theory of meaning which is a part of atomistic theory of meaning fails to be a proper theory of meaning because of its failure to see that an expression or a sentence can be meaningful on various considerations and not on the consideration of verifiability criterion alone. In this respect, we should further point out that most of the difficulties arise in connection with verifiability theory is due to the atomistic conception of meaning that it assumes in its foundation. Its approach to language is erroneous.

Language is not a collection of isolated individual sentences. Sentences, on the other hand form a corporate body where they are interlinked with each other. This brings a radical change in our conception of meaning. Since sentences are interconnected, the meaning of a sentence is decided not individually but by holistically, i.e. by the network of sentences involved in the semantic relationship. In view of this semantic holism the criterion of verifiability does no longer look to be promising. The reason is the verification of a sentence cannot be restricted to the sentence alone. Because, to verify a sentence means to verify many other sentences which are connected to it. This inevitably follows from the holistic nature of meaning which subsequently shows how inadequate is the positivists' criterion of verifiability and the notion of meaning that it seeks to support it.

We will now examine Frege's notion of 'meaning atomism' with a view to show why it fails as a theory to give an adequate account of meaning. The basic problems for Frege is: First, to explain how do propositions get their meaning? and, second, how are the truth-values of these propositions determined?

\section{${ }^{7}$ Ibid., 52.}

${ }^{8}$ G.E. Moore, Philosophical Papers (New York: Allen and Unwin Publication, 1959), 266. I have substituted 'proposition' for 'hypothesis' in this passage. See O. Hanflong, O. 1981. Logical Positivism, Oxford: Basil Blackwell Publication, 1981), 25. 


\section{ATOMISTIC THEORY OF MEANING}

\section{Drawbacks of Frege's Meaning Atomism}

On the account of Frege, sense is logically prior to reference. The sense of a proposition is same as the thought of a proposition, which for him, is the meaning of a proposition. Each proposition expresses a sense that is about the state of affairs of the world. And, if that state of affairs maps with the phenomenal world then the proposition is judged as true, and if does not map, the proposition is judged as false. Thus, for him, referent of a proposition is same as truth-value of the proposition. He enunciates that truth-value of a proposition is a composite substratum made up of concepts and objects. But he does not hold this doctrine for long due to the difficulties arise in connection with the fixing of references of propositions. For example, "The capital of India." Here, the reference of the complex expression 'the capital of India' is composed of 'the capital of ( )' and 'India.' We thus find that there are two references 'New Delhi' and 'India,' and both of them are to be satisfied to get the truth-value of the proposition. Now the question arises, among these two which one should refer 'India' or 'New Delhi.' In other words, how do we get the truth-value of the proposition 'The capital of India' whether by referring to India or by referring to New Delhi? This gives raise to a dilemma - a dilemma regarding referring to the exact object. Thus, 'meaning atomism' is not a satisfactory theory to determine whether a proposition is true or false.

Further, the problem arises due to the failure of determining the sense of a proposition. In atomistic theory of meaning, we often find propositions with having proper names. We get the meaning of a proper name through definite descriptions. So, the meaning of all proper names can be accounted for through their definite descriptions. As Frege says, every definite description has sense and from sense we can determine the referent of it. The problem subsists when we have a proper name with having more than one description, where all the descriptions are true of the proper name. For example, the proper name 'Aristotle' can be described as, "The author of the Nichomachean Ethics," "The disciple of Plato," "The teacher of the Alexzander the Great" etc. Here, could we say that each description is equivalent with other descriptions on the basis of the sense criterion? If our answer is affirmative than we make a mistake because the sense of the description "The teacher of the Alexzander the Great" becomes the same as sense of the description "The author of the Nichomachean Ethics." But this will mean that all these propositions are analytic, which necessarily implies the meaning of 'Aristotle' becomes equivalent with descriptions used for Aristotle. But this is incorrect since the meaning of 'Aristotle' is not same as its descriptions.

In Frege's account on meaning it is found that the sense of a proposition is described as the 'mode of presentation.' Here, a question arises, if the sense of an expression is the mode of presentation of its referent then it is impossible for a

(c) 2013 Satya Sundar Sethy http://www.kritike.org/journal/issue_12/sethy june2013.pdf ISSN 1908-7330 
proper name to have the same sense because of the variations found in the descriptions associated with it. Each description will present their referent in quite different ways. Thus it is stated that "a name is not true of its bearer, not as a description arbitrarily correlated with an object." ${ }^{\prime \prime}$ On these grounds, atomistic theory of meaning has expressed through Frege's theory fails to give a logically coherent account of meaning.

Atomistic theory of meaning forms the basis of the referential theory of meaning. It is so because the referential theory of meaning follows the same procedures as meaning atomism does to understand the meaning of a proposition. It states that meaning of an expression is to be understood in relation to its corresponding objects/referents. But this theory does not hold the 'meaning atomism' as free from logical problems.

\section{Problems with the Referential Theory of Meaning}

Referential theory of meaning is restricted to only assertive sentence. It's scope is not so widened to incorporate other varieties of sentences those we use in our day-to-day life for communication purposes. We do not only use those sentences but also understand them and identify their referents. In relation to the identification of the referent of an assertive proposition, referential theory of meaning claims that there is a mapping found between the sense of a proposition and the facts of the world. This forces us to claim that meaning is same as its referent. But the usage of ordinary language does not confirm to this conception. For example, "Tranz is brown." Here, the proper name Tranz does not refer to any object. So, how could we understand the meaning of the proposition? Again, if the meaning of an expression is just its referent then we would expect that any two expressions having the same referent may substitute one for the other for their meaning. If we do so, then we will be faced with insuperable difficulties explained in the following example.

i) Tom wants to meet the supreme commander of the Indian armed forces.

ii) Tom wants to meet the president of India.

Here, these two expressions have different meanings but they refer to one person. Now a question arises, could we substitute one for the other as they have same referent? We cannot do so, otherwise these two sentences will be treated as analytic, which is logically incorrect/wrong. There is no basis on which we can say that the above two propositions are identical. Thus, referential theory of meaning

${ }^{9}$ B. David, Frege's Theory of Judgment (Oxford: Clarendon Press, 1979), 56. 
which is a form of atomistic theory of meaning does not stay away with lacunas for determining the meanings of propositions.

The presence of atomistic theory of meaning is also found in the Wittgensteinean picture theory of meaning where it expresses that each proposition is a picture of a particular state of affairs of the world. The proposition will be true if the picture corresponds to the facts of the world, and if it does not, then it is judged as false. But this view is rejected on some logical grounds elucidated in the following passages.

\section{Picture Theory of Meaning and its Inadequacy}

Picture theory of meaning is a version of the atomistic theory of meaning which reflects from the explanations that a sentence is meaningful when it corresponds with the fact existing in the world. A sentence is thus meaningful by virtue of its correspondence with the external reality. The picture, that a sentence depicts, is the sense or the essence of that sentence. Generally, it is understood as the meaning of a sentence.

A question arises here, i.e. is the world divided into facts or things? Wittgenstein in his Tractatus says that the world is the totality of facts but not of things. ${ }^{10}$ But in his later work Philosophical Investigation, he revised this idea. As he explains, every fact constitutes with different objects in a determinate way. When we observe a fact we do not know about its exact nature. We come to know it through its constituent parts and the way they are combined into a whole. For example, "a chess-board, we are probably thinking of the composition out of thirty two white and thirty two black squares, but could we not also say, for instance, that it was composed of the colours black and white and the schema of squares." ${ }^{11}$ In reality, we find that facts are necessarily associated with different things or objects. So it is the aggregation of things that makes a fact. Thus, constructing a fact is a subjective concept. Since it is subjective, it differs from person to person. So, the fact that a sentence represents is not an objective kind. The idea of correspondence may thus go wrong. This trembles the ground of the picture theory of meaning which claims that the picture of a sentence corresponds to the facts of the world by virtue of which we understand the proposition.

A logical objection can be made against picture theory of meaning in particular and atomistic theory of meaning in general. That is, picture theory of meaning deals with assertive sentences whose truth-value can be determined. So there will be no problem for us to form a picture of those sentences. Now the

${ }^{10}$ See L. Wittgenstein, Tractatus Logico-Philosophicus, trans. by Von Wright, G.H. (London: Blackwell Publication, 1972), 1.1.

${ }^{11}$ L. Wittgenstein, Philosophical Investigations (London: Blackwell Publication, 2001), Sect. 47.

(C) 2013 Satya Sundar Sethy http://www.kritike.org/journal/issue 12/sethy june2013.pdf ISSN 1908-7330 
question arises regarding the negative propositions, i.e. how can we form a picture of a negative proposition? Take the proposition, "Cows are not dogs." In this case the correspondence theory fails to determine the truth-value of the proposition. This is so because there are no such circumstances where we can form the picture of the state of affairs expressed by the proposition. Thus we are unable to refer to the fact that the proposition is stating about. Hence, on the account of picture theory of meaning it is a meaningless proposition. But could we claim so? If the answer is 'yes' then it indicates that there is something essentially wrong with the picture theory of meaning.

Further, in atomistic theory of meaning we find that every proposition has a definite sense. Since it provides the definite and determinate sense it corresponds to the facts of the world. Thus, each proposition is meaningful based on its corresponding facts those exist in the phenomenal world. But this does not offer a meaning theory that can account for all sorts of propositions in our language.

For example, suppose someone says "leave this or that open." Here, the sentence nevertheless provides a definite sense. Rather, it holds the indefinite sense that would really not be a sense at all. -This is like: "An indefinite boundary is not really a boundary at all." Here, one thinks perhaps: if I say "I have locked up the man in the first room -there is only one door left open"- then I simply have not locked him at all; his being locked in is a shame. One would be inclined to say here: you have not done any thing at all. An enclosure with a hole in it is as good as none -but is that true ${ }^{12}$

To hold the criterion of meaningfulness of a proposition, picture theory of meaning states that it is the elementary proposition which states about the facts of the world. We determine the truth-value of an elementary proposition on the basis of its correspondence to the worldly affairs. A question pops up, i.e. is it necessary that all the propositions should be reducible to elementary propositions? Further, do we communicate with others only through elementary propositions? Obviously not, yet we understand the meaning of the propositions without deducing them to elementary propositions. In this sense, atomistic theory of meaning fails as a theory to explain how we understand the meaning of a proposition.

In atomistic theory of meaning we often find that propositions are consisting of proper names. The meaning of a proper name is determined by the

${ }^{12}$ Ibid., Sect. 99.

(C) 2013 Satya Sundar Sethy http://www.kritike.org/journal/issue 12/sethy june2013.pdf ISSN 1908-7330 
object it denotes. This view is criticized in the Philosophical Investigation. As Wittgenstein argues, this view is the result of confusion between the bearers of a name with the meaning of a name. For example, to say, "Plato dies" implies that the bearer of the name dies but not the meaning of the name dies. "It is a matter of fact that a man's name does not lose its meaning when he is destroyed" (Philosophical Investigation, Sec.55). The meaning of a name consists of various descriptions which are used for identifying the person which bears that name. But a name can have a meaning even though nothing exists corresponding to it, e.g. Dragon. In this connection, Wittgenstein admits that there may be cases where we have to say "the word '____ would have no meaning if a certain object 0 did not exist." But in these cases, the object 0 is not anything named by the word in question, and our statement is in fact a mere truism..$^{13}$

In picture theory of meaning, it is viewed that elementary propositions are the pictures of reality and they state the facts about the world. So, there is a 'logical form' found between the picture of a proposition and the facts of the world. This analysis does not work in all the cases of ordinary language. For example, consider a case where a person made a gesture, familiar to Neopolitans as meaning something like disgust or contempt, and then he asks what is the logical form of that. To look for a logical form in a remote possibility, the view is that, a proposition is a picture of reality, i.e. what it describes is untenable.

Another difficulty is prominently figured in the atomistic theory of meaning, i.e. in reference to the relation between the word and the object it denotes or, a sentence and the situation it describes. The question frames as, how is it possible to make a correlation between the language and the world? According to the atomists, it is possible by virtue of performing a mental act, namely intending that we can make a relation between the word and the object. This resulted into confusion with regard to correctly identifying the object. For example, $\mathrm{X}$ said to $\mathrm{Y}$ 'Tom visited yesterday.' What is it that $\mathrm{Y}$ understands from this sentence? Is it 'Tom Rant' or 'Tom Hick' who visited yesterday? In order to confirm this, $\mathrm{Y}$ asks further, who is that person visited yesterday- is it Tom Rant or Tom Hick? This example clearly shows that 'mental act of intending' does not work in all the cases for understanding the meaning of a proposition. Hence, atomistic theory of meaning is too rigid and too narrow to give an indubitable account for the semantic behavior of ordinary language.

One may point out that atomistic theory of meaning can function well with the support from ostensive definition where the truth-value of each proposition is determined ostensively. But the method of ostensive definition has a very limited scope. It may fail to explain the meaning of all segments of language use. For example, a teacher says to a student, "This is blue by pointing out the

${ }^{13}$ See G. Pitcher, The Philosophy of Wittgenstein (New Delhi: Prentice Hall of India Private Limited, 1972), 182.

(C) 2013 Satya Sundar Sethy

http://www.kritike.org/journal/issue 12/sethy june2013.pdf

ISSN 1908-7330 
finger to a blue pen." In this case, the student might thought the term 'blue pen' is a name, or it may be the term 'blue' which will occur when 'blue pen' comes to his preview. Moreover, for that student 'blue pen' is the blue color. ${ }^{14}$ This shows that the very premise of the atomistic theory that the criterion of meaningfulness of a sentence is decided by its truth condition is untenable.

This theory claims, meaning of a sentence depends upon the meaning of its constituent words of that sentence. But this has failed on a logical ground. Take an example of "The father of Annette." 15 Here question arises, how does the meaning of this expression depend on the meaning of its constituent part? In this sentence, the singular term "Annette" refers to Annette, while the complex term 'the father of is designated as " $t$ " in the form of a singular term. Hence, it refers to the father of that person, to whom " $t$ " refers. As a result, we are able to understand the meaning of this sentence and do communicate in our language. But if we know the meaning of each and every word of the sentence like, 'the,' 'of,' father' and 'Annette' and try to get the meaning out of it, we are not able to get the proper meaning of the sentence. So, we need a holistic view to understand this sentence, i.e. "each constituent word of the sentence must have the ontologically neutral sense of making the systematic contribution to the meaning of the sentence in which they occur." ${ }^{16}$ In this sense meaning works holistically.

Finally, there is an important issue to be addressed concerning to the relationship between the Tarskian model of ' $\mathrm{T}$-schema' and the atomistic theory of meaning. The question here is how far the Tarskian model is successful in defending the atomistic theory of meaning.

\section{Tarski and the Problem of 'T-Schema'}

Tarski is one of the supporters of atomistic theory of meaning. His schema 'Convention- $\mathrm{T}$ ' provides a well-formed definition of truth theory which satisfies the atomistic theory of meaning. The definition that he offers claims that the two following principles must be satisfied for an individual sentence to be judged as true. First of all, it should be 'formally correct' and secondly, it must be 'materially adequate.' His 'T-Schema' is:

(T) $\quad S$ is true if and only if $\mathrm{P}$.

\footnotetext{
${ }^{14}$ This analysis is found in an elaborate fashion in M. Schlick, Philosophical Papers (London: Dordrecht Publication, 1979), 458. See G.H.R. Parkinson,G.H.R., An Encyclopedia of Philosophy (London: Rout ledge Publication, 1988), 35.

${ }^{15}$ This example and its analysis has been taken from D. Davidson, "Truth and Meaning," in Inquiries into Truth and Interpretation (Oxford: Clarendon Press, 1984), 17-18.

${ }^{16} \mathrm{Ibid} ., 22$.

(C) 2013 Satya Sundar Sethy http://www.kritike.org/journal/issue 12/sethy june2013.pdf ISSN 1908-7330 


\section{ATOMISTIC THEORY OF MEANING}

Here ' $S$ ' is the name of a sentence which can be judged as either true or false. ' $\mathrm{P}$ ' is the actual sentence which states about the facts or state of affairs of the world. In short, his definition states that ' $S$ ' is true if and only if it is about the fact which is found in the empirical world. For example, "snow is white' is true if and only if snow is white." The truth-value of the sentence 'snow is white' depends on 'snow' and the property of being 'white.' The sentence will be judged as true only when all these things are verified by our observational sense data, otherwise the sentence is false.

The problem arises when we are asked, "how are we to tell whether a particular T-sentence is itself true." It is followed by a subsequent question, "how do we know what the meaning of an expression is about"? Again, it is argued that "how the intentional mental states or intentional sentences refer to things/objects"? Such as, "He is in bad mood." Some other sentences like, "Punctuality is praiseworthy," "Honesty is desirable," "Every particle of snow above a certain size is white" etc. These propositions have no particular references yet we understand these propositions. How is it possible to understand these propositions? In this regard, Putnam states that Tarski's truth predicates have nothing to do with semantics or the common conception of truth. In his words, "as a philosophical account of truth, Tarski's theory fails as badly as it is possible for an account to fail” (Davidson, 1990, 285). While criticizing Taski's truth theory, Max Black and Dummett are of the opinion that "Tarski did not define the concept of truth, even as applied to sentences. What he showed is how to define a truth predicate for each of a number of well-behaved languages." 17

Repudiating Tarski's truth theory, Kripkee said that anyone who knows how the bival condition operates in English must know that the sentence concern expresses a truth irrespective of whether he knows the meaning of that sentence. For example, the sentence "Horses are called horses" is true without knowing the meaning of the proposition expressed by that sentence. It is an uninformative sentence. So we are not getting any new information from it. It only expresses analytic truth which is true by definition.

Counteracting to Tarski's truth theory it may be stated that it is neither possible to understand the meaning of a sentence by the help of its constituent words nor the sentence is itself capable of acquiring the meaning without corroborating with other sentences. Thus, we need a holistic view for understanding the meaning of a sentence which implies a sentence won't confirm our experiences exclusively or completely independent of other sentences of a

${ }^{17}$ D. Davidson, “The Structure and Content of Truth," in Journal of Philosophy, 87 (1990), 285.

(c) 2013 Satya Sundar Sethy http://www.kritike.org/journal/issue 12/sethy june2013.pdf ISSN 1908-7330 
language. For example, the sentence "The sun is behind the cloud"18 is true if all the following conditions are satisfied, such as,

i) It is day time.

ii) The sun has risen.

iii) It is not a pitch dark.

iv) More people are awake than asleep.

v) Millions of automobiles are emitting smoke in to the atmosphere, and so on. This example shows a sentence won't be understood in isolation from other sentences.

From these above analyses, we assert that atomistic theory of meaning by nature is too narrow. It does not capture the complexities of meaning. So we need to look for an alternative conception of meaning, i.e. holistic approach to meaning. It submits that in order to understand the meaning of a sentence we need to understand some other sentences within a particular paradigm of language. This suggests for the holistic view of meaning, i.e. meaning works holistically.

Department of Humanities and Social Science, Indian Institute of Technology Madras, India

\section{References}

Ammerman, R. ed., Classics of Analytic Philosophy (New Delhi: Mc Graw-Hill Publishing Company Ltd., 1965).

Carnap, R., The Logical Syntax of Language (New York: Harcourt, 1937).

David, B., Frege's Theory of Judgment (Oxford: Clarendon Press, 1979).

Davidson, D., "The Structure and Content of Truth," in Journal of Philosophy, 87

(1990), 279-328.

, "Truth and Meaning," in Inquiries into Truth and Interpretation

(Oxford: Clarendon Press, 1984).

Hanflong, O., Logical Positivism, Oxford: Basil Blackwell Publication, 1981).

Hempel, C., "On the Logical Positivists' Theory of Truth, in Analysis 2 (1935), 49-

59.

${ }^{18}$ This example was borrowed from D. Wiggins, "Meaning and Truth Conditions: from Frege's Grand Design to Davidson's," in A Companion to the Philosophy of Language, eds. by Hale, B. and Wright, C. (UK: Blackwell Publishers, 1999), 5-6.

(C) 2013 Satya Sundar Sethy http://www.kritike.org/journal/issue_12/sethy june2013.pdf ISSN 1908-7330 


\section{ATOMISTIC THEORY OF MEANING}

Moore, G.E., Philosophical Papers (New York: Allen and Unwin Publication, 1959).

Munitz, M., Contemporary Analytic Philosophy (New York: Macmillan Publishing Co., INC, 1981).

Parkinson, G.H.R., An Encyclopedia of Philosophy (London: Rout ledge Publication, 1988).

Pitcher, G., The Philosophy of Wittgenstein (New Delhi: Prentice Hall of India Private Limited, 1972).

Schlick, M., Philosophical Papers (London: Dordrecht Publication, 1979).

Waismann, F. ed., "Meaning and Verification," in Essential Readings in Logical Positivism (Oxford: Basil Blackwell Publication, 1981).

Wiggins, D., "Meaning and Truth Conditions: from Frege's Grand Design to Davidson's," in A Companion to the Philosophy of Language, eds. by Hale, B. and Wright, C. (UK: Blackwell Publishers, 1999).

Wittgenstein, L., Philosophical Investigations (London: Blackwell Publication, 2001).

, Tractatus Logico-Philosophicus, trans. by Von Wright, G.H. (London: Blackwell Publication, 1972).

Tractatus Logico-Philosophicus, trans. by Von Wright, G.H. (London: Blackwell Publication, 1972). 